\title{
BMJ Open Natural history of histologically confirmed high-grade cervical intraepithelial neoplasia during pregnancy: meta-analysis
}

Cheng Chen, ${ }^{1,2}$ Yu Xu (D) , ${ }^{3}$ Wu Huang, ${ }^{1,2}$ Yi Du, ${ }^{3}$ Cui Hu ${ }^{4}$

To cite: Chen C, Xu Y, Huang W, et al. Natural history of histologically confirmed highgrade cervical intraepithelial neoplasia during pregnancy: meta-analysis. BMJ Open 2021;11:e048055. doi:10.1136/ bmjopen-2020-048055

- Prepublication history and additional supplemental material for this paper are available online. To view these files, please visit the journal online (http://dx.doi.org/10.1136/ bmjopen-2020-048055).

Received 17 December 2020 Accepted 06 August 2021

Check for updates

(c) Author(s) (or their employer(s)) 2021. Re-use permitted under CC BY-NC. No commercial re-use. See rights and permissions. Published by BMJ.

${ }^{1}$ Department of Obstetrics and Gynaecology, Pidu District People's Hospital, Chengdu, China

${ }^{2}$ Department of Obstetrics and Gynaecology, The Third Affiliated Hospital of Chengdu Medical College, Chengdu, China ${ }^{3}$ Department of Obstetrics and Gynaecology, West China Second University Hospital, Sichuan University, Chengdu, China

${ }^{4}$ Department of Obstetrics and Gynaecology, People's Hospital of Mianzhu City, Deyang, China

Correspondence to

Dr Yu Xu; xuyu@stu.scu.edu.cn

\section{ABSTRACT}

Objectives This study aimed to conduct a meta-analysis of estimates of the natural history of high-grade cervical intraepithelial neoplasia (CIN) during pregnancy. Setting Studies examining the clinical courses of histologically confirmed high-grade CIN during pregnancy. Participants We searched PubMed, Web of Science and Embase for eligible studies. Studies were included if they reported the data regarding the natural history of histologically confirmed high-grade CIN during pregnancy. Final estimates were from the meta-analysis of 10 eligible studies.

Primary outcome measures The regression rate, persistence rate and progression rate of histologically proven untreated high-grade CIN during pregnancy.

Results A total of 10 original studies were included in this meta-analysis. During pregnancy, the regression rate, persistence rate and progression rate of high-grade CIN were $40 \%$ (95\% Cl $35 \%$ to $45 \%), 59 \%$ (95\% Cl $54 \%$ to $64 \%$ ) and $1 \%(95 \% \mathrm{Cl} 0 \%$ to $2 \%$ ), respectively. There was moderate heterogeneity among the studies. The results of the subgroup meta-analysis show that the pooled rates of regression and persistence during pregnancy were $59 \%$ (95\% Cl $54 \%$ to $65 \%$ ) and $40 \%$ (95\% Cl $35 \%$ to $45 \%$ ) for CIN2, and $29 \%$ (95\% Cl $25 \%$ to $33 \%$ ) and $70 \%$ (95\% Cl $65 \%$ to $73 \%$ ) for CIN3.

Conclusions During pregnancy, the majority of histologically confirmed high-grade CIN would be persistent or regressed to lower grade CIN or normal. However, it is still worth noting that a small percentage of high-grade CIN would progress to cervical cancer during pregnancy.

\section{INTRODUCTION}

High-grade cervical intraepithelial neoplasia (CIN) is thought to be cervical precancerous lesions, which include CIN2 and CIN3. ${ }^{2}$ High-grade CIN is caused by the human papillomavirus (HPV), which is the most common sexually transmitted infection in women, up to $75 \%$ of females will become infected with HPV during their lifetime. ${ }^{1}$ Fortunately, only a minority of women infected will progress to high-grade CIN and potentially even cancer when left untreated. ${ }^{1-3}$

\section{STRENGTHS AND LIMITATIONS OF THIS STUDY}

$\Rightarrow$ This is the first meta-analysis regarding this topic.

$\Rightarrow$ This meta-analysis was conducted following the Preferred Reporting Items for Systematic Reviews and Meta-Analyses guidelines. Also, scientific and reliable methodological and statistical methods can ensure the reliability of the results of our study.

$\Rightarrow$ We included only the studies published in the peerreviewed English journals because of the limited resource and authors' linguistic proficiency.

During pregnancy, about 2-7 in 100 women will experience abnormal cervical cytological findings, which is similar to that of their age-matched non-pregnant peers, and about $1.3 \%-2.7 \%$ of pregnant women will be affected by different degrees of CIN. ${ }^{4-7}$ Although the overall incidence of invasive cervical cancer among pregnant women with biopsy-proven diagnosis of high-grade CIN is fairly low, ${ }^{8}$ cervical cancer is the most common gynaecological cancer found during pregnancy, with an estimated incidence of 1.5-12 of every 100000 pregnancies. ${ }^{4-11}$

Over the years, the management protocols for CIN during pregnancy have gone through from an aggressive biopsy and treatmentbased course of action to a more conservative and expectant way. ${ }^{9}$ 12-16 At present, the main purpose of management for CIN during pregnancy is to exclude invasive cervical cancer. ${ }^{17}$ Once the invasive disease has been excluded through a comprehensive diagnostic workout, treatment of CIN can be safely postponed until after the puerperium. ${ }^{17}$ This shift was based on the consensus that the risk of high-grade CIN to progress to invasive cervical cancer during pregnancy and the postpartum period is very low. ${ }^{17}$ However, the available data on the natural history of high-grade CIN during and after pregnancy are heterogeneous. ${ }^{18-21}$ With all this in mind, we conducted this meta-analysis 
to statistically synthesise the data of studies examining the clinical course of high-grade CIN during pregnancy.

\section{MATERIAL AND METHODS}

We conducted this meta-analysis following the Preferred Reporting Items for Systematic Reviews and MetaAnalyses guidelines. ${ }^{22}$ The protocol of this study was registered at PROSPERO, the registration number is CRD42020220977. Two members of our team independently performed literature searches, data extraction and quality assessment in duplicate. Disagreements were resolved by discussion and, if necessary, a consensus was reached with the involvement of a third investigator.

\section{Literature search}

We searched three electronic databases (PubMed, Embase and the Web of Science) for studies between database inception and 15 October 2020. The language was restricted to English because of the limited resource and authors' linguistic proficiency. To define the study population, we used the Boolean operator (ie, AND, OR) to combine the following keywords: "cervical intraepithelial neoplasia", "cervical intraepithelial neoplasm", "pregnancy" and "pregnant women" (see online supplemental material 1 for the details of search strategies). We also hand searched the reference lists of all included papers.

\section{Study selection}

Records obtained from the database searches and hand searches were imported into a local reference manager (EndNote V.X9). Duplicates were removed, and all records were screened by title and abstract. Full texts of the items identified by title and abstract screening were obtained and thoroughly evaluated for eligibility by two authors independently.

Articles were included in this meta-analysis according to the following predefined inclusion criteria: being a fulltext original article published in a peer-reviewed English journal; reported on outcomes of pregnant women with histologically proven CIN2 or CIN3 who were not treated at diagnosis, were monitored during pregnancy and had a diagnosis (histological or cytological) available at the end of the study period; defining the length of the follow-up period; having clear definitions of regression, persistence and progression of the disease.

Articles were excluded for the following reasons: reporting duplicated data; including fewer than 30 patients; published as conference abstracts, commentary, series case reports, letters or short communications; and including patients with a diagnosis of low-grade CIN.

\section{Data extraction}

For all included studies, data regarding the following variables were collected: name of the first author, year of publication, the design and setting, geographical region, the size of the study cohort, the number of participants with the outcomes of interest, method of cervical evaluation after delivery, regression rate, persistence rate, progression rate and duration of follow-up.

The above-mentioned data were identified and extracted from the reports by hand and desktop search engines to improve accuracy. A dedicated form was developed before the data extraction. Further attempts to obtain relevant but unavailable quantitative data were made by contacting the corresponding authors. To make sure the integrity of the data gathered, the results of data extraction were rechecked by a third investigator.

We accepted the definitions of regression, persistence and progression used in each study, recognising that there would be heterogeneity in definitions across studies. In general, regression of high-grade CIN was defined as regression to low-grade (CIN1) or normal detected in the follow-up period compared with the initial visit. Persistence of the disease was defined as persistence of high-grade CIN regardless of CIN2 or CIN3. Progression of high-grade CIN was defined as histological evidence of microinvasive carcinoma or invasive cancer at a subsequent visit when compared with the initial consultation.

\section{Quality assessment}

To assess the quality of the included studies, we used the critical appraisal tool for prevalence studies with further guidance from Munn et $a l^{2324}$ where each study was judged on nine questions answered by 'Yes', 'No' or 'Unclear'. Studies were categorised based on the percentage of 'No' answers as high quality $(\leq 49 \%)$, moderate quality ( $50 \%-$ $69 \%)$ or low quality $(\geq 70 \%) .^{23}$

\section{Statistical analysis}

We defined regression, persistence and progression rates as the ratio of the observed number of women with a given outcome divided by the number of women attending in that follow-up time. Using the metaprop command in STATA V.15, we meta-analysed pooled proportions for each outcome. We used the exact binomial score testbased CIs with the Freeman-Tukey double arcsine method to stabilise the variances for individual studies, in which many of the proportions were close to or at the margins of the possible interval $(0$ or $100 \%) .^{25}$

The heterogeneity between studies was evaluated by the $\mathrm{I}^{2}$ metric of inconsistency, and $\mathrm{I}^{2}$ values of $25 \%, 50 \%$ and $75 \%$ were considered low, moderate and high heterogeneity, respectively. ${ }^{26}$ When low statistical heterogeneity exists, data would be pooled using a fixed-effects model. If there was moderate or severe heterogeneity among the included studies, considering that there may be a significant difference in the natural courses between CIN2 and CIN3, this category would be used to conduct subgroup analyses by strata of defined study attribute to present subgroup-specific meta-analysis effect estimates.

Visual inspection of funnel plots and the Egger's regression asymmetry test $(\mathrm{p}<0.10)$ were used to examine the possible presence of publication bias only when there were at least 10 studies in the meta-analysis. ${ }^{27}$ The statistical software (Stata, V.15.1/IC; StataCorp) was used for 


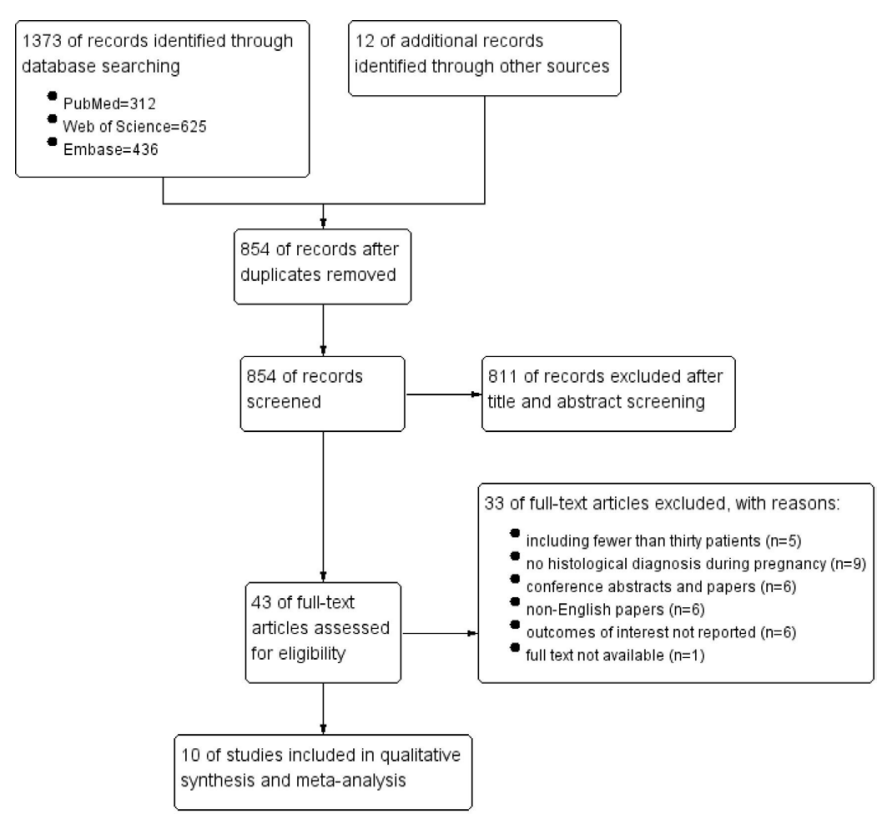

Figure 1 Study selection flow chart. all data analyses, two-tailed $\mathrm{p}<0.05$ was considered statistically significant.

\section{RESULTS \\ Search results}

A total of 1385 records were identified through the literature searches. After duplicate removal, 854 items were screened by title and abstract, 43 items were assessed in full text, and 10 studies including 832 patients were eventually included in this systematic review and meta-analysis. The process of study selection is described in figure 1 .

\section{Characteristics and quality of included studies}

Table 1 shows the characteristics of the included studies. ${ }^{28-37}$

These studies were published between 1999 and 2020 including 10 study populations from different countries. The sample size of these studies ranged from 32 to 160 . Among them, a total of six studies were retrospective cohort studies, ${ }^{293134-37}$ the rest of them were all prospectively designed. ${ }^{2830} 3233$ As for the duration of postpartum

Table 1 Characteristics of included studies

\begin{tabular}{|c|c|c|c|c|c|c|}
\hline Study & Country & Design of study & $\begin{array}{l}\text { Study } \\
\text { span }\end{array}$ & $\begin{array}{l}\text { Size of } \\
\text { sample }\end{array}$ & $\begin{array}{l}\text { Methods of postpartum } \\
\text { diagnosis }\end{array}$ & $\begin{array}{l}\text { Point of } \\
\text { postpartum } \\
\text { follow-up }\end{array}$ \\
\hline Schuster et al $2018^{35}$ & Australia & $\begin{array}{l}\text { Retrospective } \\
\text { unicentre cohort study }\end{array}$ & 2010-2015 & 35 & $\begin{array}{l}\text { Cervical cytology or/and } \\
\text { colposcopy-directed biopsy; } \\
\text { cervical excision }\end{array}$ & $6-8$ weeks \\
\hline $\begin{array}{l}\text { Mailath-Pokorny et } \\
\text { al } 2016^{34}\end{array}$ & Austria & $\begin{array}{l}\text { Retrospective } \\
\text { unicentre cohort study }\end{array}$ & 2005-2010 & 34 & $\begin{array}{l}\text { Cervical cytology or/and } \\
\text { colposcopy-directed biopsy }\end{array}$ & 8 weeks \\
\hline Wu et al $2014^{33}$ & China & $\begin{array}{l}\text { Prospective unicentre } \\
\text { cohort study }\end{array}$ & 2007-2010 & 114 & $\begin{array}{l}\text { Cervical cytology or/and } \\
\text { colposcopy-directed biopsy; } \\
\text { cervical excision }\end{array}$ & 8-12 weeks \\
\hline Ueda et al $2009^{31}$ & Japan & $\begin{array}{l}\text { Retrospective } \\
\text { unicentre cohort study }\end{array}$ & 1994-2007 & 32 & $\begin{array}{l}\text { Cervical cytology and } \\
\text { colposcopy-directed biopsy }\end{array}$ & 12 weeks \\
\hline Serati et al $2008^{30}$ & Italy & $\begin{array}{l}\text { Prospective unicentre } \\
\text { cohort study }\end{array}$ & 2003-2007 & 36 & $\begin{array}{l}\text { Colposcopy-directed biopsy or } \\
\text { cervical excision }\end{array}$ & $8-12$ weeks \\
\hline Vlahos et al $2002^{29}$ & Greece & $\begin{array}{l}\text { Retrospective } \\
\text { unicentre cohort study }\end{array}$ & 1988-1998 & 78 & $\begin{array}{l}\text { Colposcopy-directed biopsy or } \\
\text { cervical excision }\end{array}$ & 8-12 weeks \\
\hline Yost et al $1999^{28}$ & USA & $\begin{array}{l}\text { Prospective unicentre } \\
\text { cohort study }\end{array}$ & 1995-1996 & 153 & $\begin{array}{l}\text { Cervical cytology and } \\
\text { colposcopy-directed biopsy }\end{array}$ & $6-12$ weeks \\
\hline Grimm et al $2020^{37}$ & Germany & $\begin{array}{l}\text { Retrospective } \\
\text { unicentre cohort study }\end{array}$ & 2001-2017 & 60 & $\begin{array}{l}\text { Cervical cytology or/and } \\
\text { colposcopy-directed biopsy; } \\
\text { cervical excision }\end{array}$ & 8-12 weeks \\
\hline
\end{tabular}


Table 2 Natural history of high-grade CIN during pregnancy

\begin{tabular}{lcrrr}
\hline \multicolumn{5}{c}{ High-grade CIN } \\
\cline { 2 - 5 } & Number of studies & Rate & $95 \%$ CI & Heterogeneity \\
\hline Regression & 10 & $40 \%$ & $35 \%$ to $45 \%$ & $55 \%$ \\
\hline Persistence & 10 & $59 \%$ & $54 \%$ to $64 \%$ & $57.1 \%$ \\
\hline Progression & 6 & $1 \%$ & $0 \%$ to $2 \%$ & $0.0 \%$ \\
\hline CIN, cervical intraepithelial neoplasia. & & & \\
\hline
\end{tabular}

follow-up, the majority of the study populations were followed up for 8-12 weeks. ${ }^{28-34} 3637$ After delivery, the actual management of high-grade CIN mainly depended on cytological and histological findings and the risk of cervical cancer. ${ }^{28-37}$

The results of quality assessment for all included studies $^{28-37}$ are shown in online supplemental material 2. The appraisal of methodological aspects for the included studies was performed by our independent investigators according to the Joanna Briggs Institute's critical appraisal checklist, ${ }^{23} 24$ all the included studies have no more than one 'No' answers indicating that they were all at fairly low risk of bias.

\section{Natural history of histologically proven high-grade CIN during pregnancy}

A total of 10 studies reported the clinical courses of histologically proven high-grade CIN during pregnancy. Table 2 shows the natural history of high-grade CIN during pregnancy.

Regression rates of high-grade CIN during pregnancy

In total, 10 studies ${ }^{28-37}$ reported regression rates of highgrade CIN during pregnancy. The pooled regression rate for high-grade CIN during pregnancy was 40\% (95\% CI $35 \%$ to $45 \%$ ), but the heterogeneity among these studies was moderate to high $\left(\mathrm{I}^{2}=55.0 \%\right)$ (figure $\left.2 \mathrm{~A}\right)$. We performed the subgroup meta-analysis by dividing highgrade CIN into CIN2 and CIN3, its result shows that the pooled regression rates for CIN2 and CIN3 were $59 \%$ (95\% CI $54 \%$ to $65 \%$ ) and $29 \%$ (95\% CI $25 \%$ to $33 \%)$, respectively (figure $2 \mathrm{~B}$ ). The funnel plots (online supplemental material 3) and Egger's test $(p=0.913)$ indicate that there was a low risk of publication bias.

\section{Persistence rates of high-grade CIN during pregnancy}

The meta-analysis of 10 studies shows that the pooled persistence rate of high-grade CIN during pregnancy was $59 \%$ (95\% CI $54 \%$ to $65 \%$ ) (figure 3A). Similarly, due to the existence of moderate-to-high heterogeneity $\left(\mathrm{I}^{2}=57.1 \%\right)$ among these studies, we employed subgroup meta-analysis to calculate the persistence rate of highgrade CIN during pregnancy. The result of the subgroup meta-analysis of the included studies ${ }^{28-37}$ demonstrates that $40 \%(95 \%$ CI $35 \%$ to $45 \%)$ of CIN2 and $70 \%(95 \%$ CI $65 \%$ to $73 \%$ ) of CIN3 would be persistent during pregnancy (figure 3B). We found no small study effects existed among these studies by the visual inspection of funnel plots (online supplemental material 4) and the Egger's test $(\mathrm{p}=0.373)$.

\section{Progression rates of high-grade CIN to cervical cancer during} pregnancy

Six studies 282932333637 reported the incidence of highgrade CIN progressing to cervical cancer during pregnancy. According to the meta-analysis of these studies, $1 \%(95 \%$ CI $0 \%$ to $2 \%)$ of high-grade CIN would progress to cervical cancer (figure 4 ). There was no significant heterogeneity among these studies $\left(\mathrm{I}^{2}=0.0 \%\right)$. The Egger's test $(p=0.105)$ shows that there was no bias of publication.

\section{DISCUSSION}

We perform cytological screening and colposcopy during pregnancy with the main goal of confirming that there is no invasive cervical cancer that exists. ${ }^{13-16}$ Thus, abnormal screening findings in gestational time lead to the employment of colposcopy and even colposcopyguided biopsy if necessary, this is the same as for nonpregnant women. ${ }^{15} 38$ However, there are some aspects of cervical screening during pregnancy that deserve our attention. During pregnancy, the CIN lesions are thought to be cytometrically identical to those of patients without pregnancy, but it is more difficult for clinical pathologists to interpret them correctly because of the interference from the physiological changes of exfoliated cells in the reproductive tract during pregnancy. ${ }^{6} 3940$ What is more, changes in hormone levels during pregnancy can lead to a series of physiological changes in the cervix (eg, mucus overproduction, cervical hyperemia and hyperplasia of endocervical glands), all these changes can compromise the diagnostic power of colposcopy. ${ }^{41} 42$ Thus, pregnant patients with suspected CIN should be assessed and consequently actively surveilled in specialised clinics.

There have been some studies with regard to the natural history of untreated CIN during pregnancy. ${ }^{19-21}$ 43-46 However, most of them did not investigate the different courses for different degrees of CIN, or the majority of diagnoses of CIN in these studies were based on cytological findings. By meta-analysis, our study found that the majority of high-grade CIN will persist or regress to lowgrade CIN or normal during pregnancy. This conclusion is consistent with the results of other studies. ${ }^{31} 323542-44$ Compared with non-pregnant patients, the regression rate of high-grade lesions of pregnant women is higher. ${ }^{47} 48$ Including 36 studies that involved 3160 non-pregnant women with CIN2, the systematic review and meta-analysis conducted by Tainio et $a l^{48}$ found that the regression rate and persistence rate of lesions were $50 \%$ (95\% CI $43 \%$ to $57 \%$ ) and $32 \%$ (95\% CI $23 \%$ to $42 \%)$ at 24 months after diagnosis. At present, the status of HPV infection is considered to be a major factor affecting the clinical outcome of high-grade lesions. ${ }^{49}$ Bogani et $a t^{49}$ reported that patients with high-risk HPV-positive high-grade CIN are at increased risk of disease recurrence when 
A

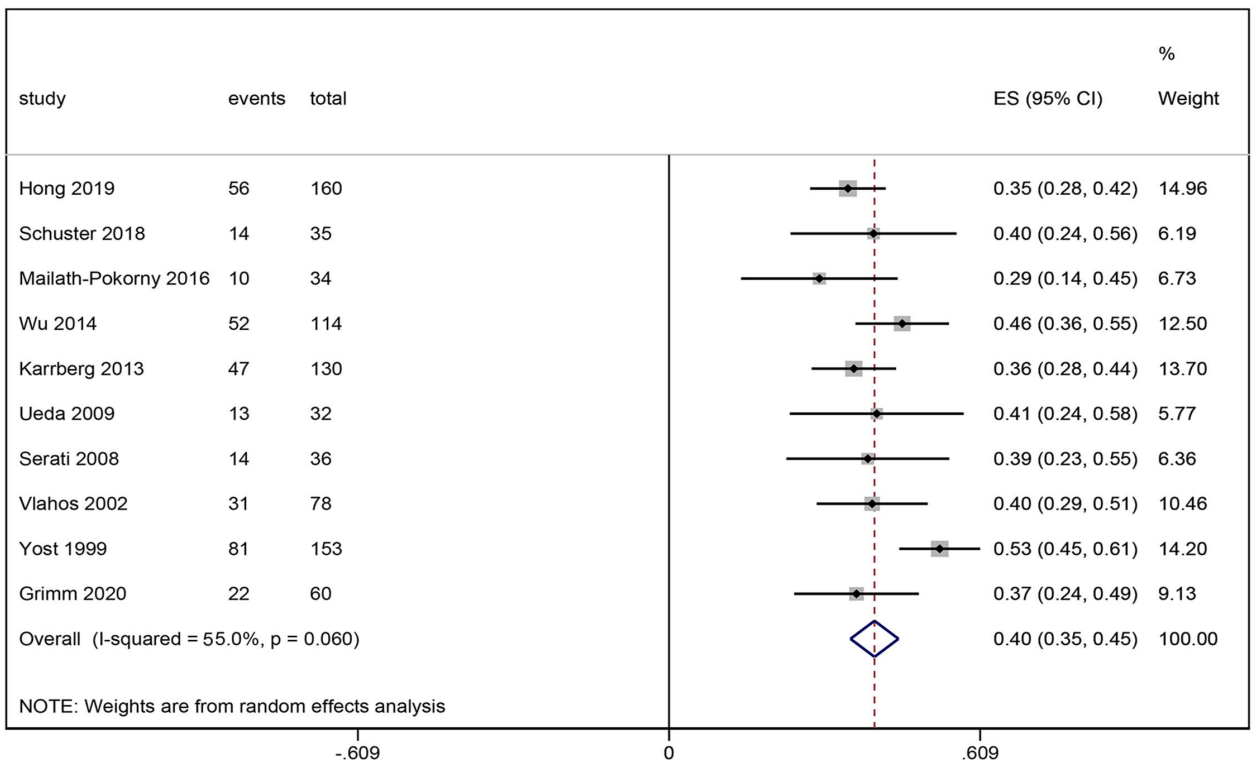

B

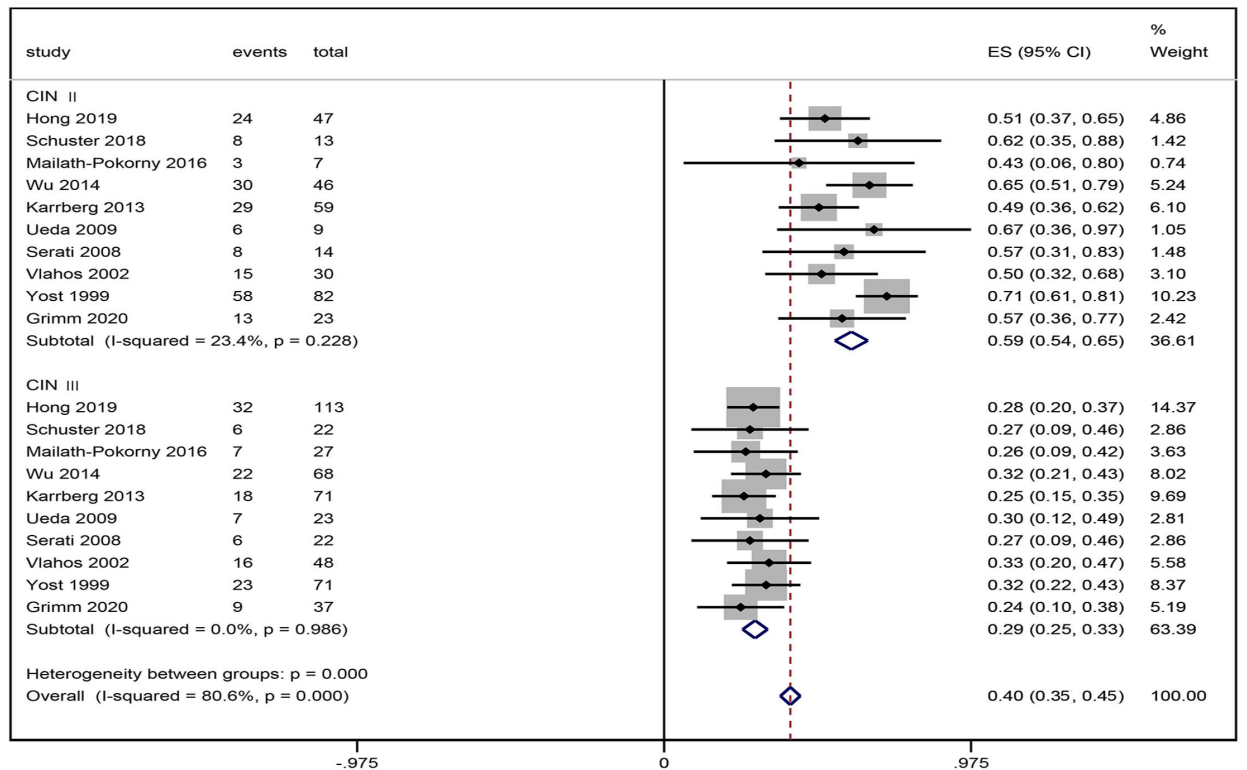

Figure 2 Forest plot of regression rates of high-grade CIN (A, non-subgroup analysis; B, subgroup analysis). CIN, cervical intraepithelial neoplasia.

compared with women who do not have an infection of high-risk HPV. In terms of the possibility for high-grade CIN progressing to invasive cervical cancer during pregnancy, the reported data were generally consistent. $3650-52$ The reported progression data varied from $0.3 \%$ to $1.2 \%$, which is mainly due to the large heterogeneity of the definition of disease progression among these studies. Some authors even think that the progression from CIN3 to invasive cervical cancer between the antepartum and the postpartum period is an unlikely event. ${ }^{11}$ Invasive cervical cancer found after delivery is not excluded as a missed diagnosis during pregnancy.

Based on the recent American Cancer Society and American Society of Colposcopy and Cervical
Pathology guidelines, high-grade lesions of the cervix among pregnant women should be actively surveilled with repeat cytology and colposcopy at intervals no shorter than 3 months. ${ }^{15}{ }^{53}$ However, the necessity of repeated colposcopy during pregnancy for pregnant women with high-grade CIN has been questioned. ${ }^{42}$ On one hand, the repeated colposcopy during pregnancy may result in insecurity to the pregnancy, an increase of anxiety and worry in patients, and a decline in patient compliance. On the other hand, repeated colposcopy for high-grade CIN during pregnancy is of little practical significance when the fact that the risk for high-grade CIN to progress to invasive cervical cancer is fairly low is taken into account. 
A

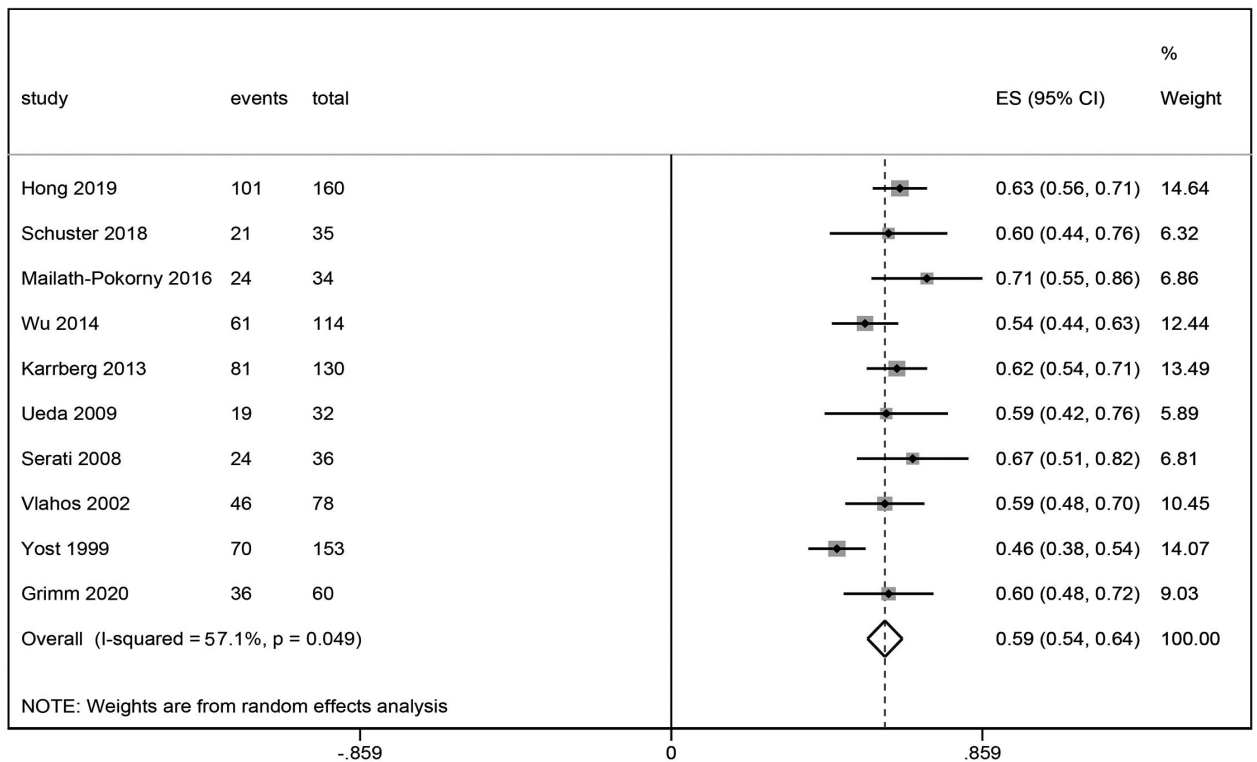

B

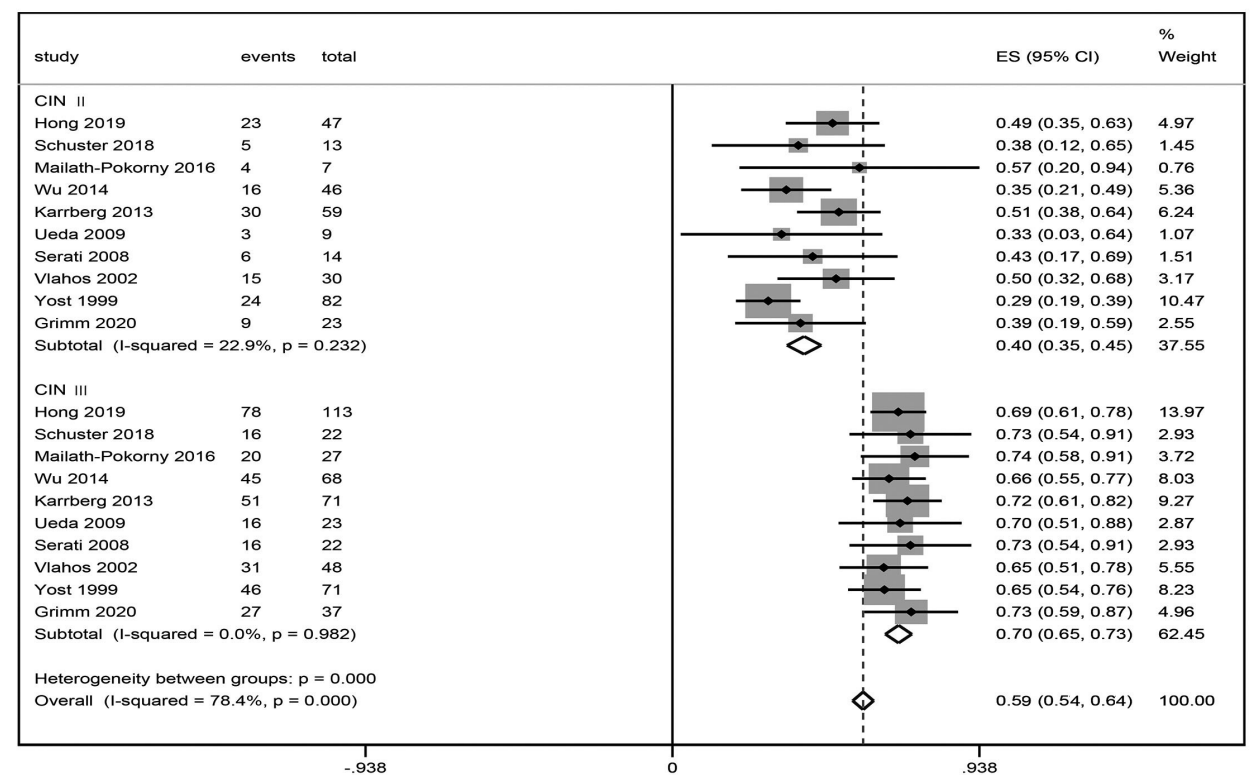

Figure 3 Forest plot of persistence rates of high-grade CIN (A, non-subgroup analysis; B, subgroup analysis). CIN, cervical intraepithelial neoplasia.

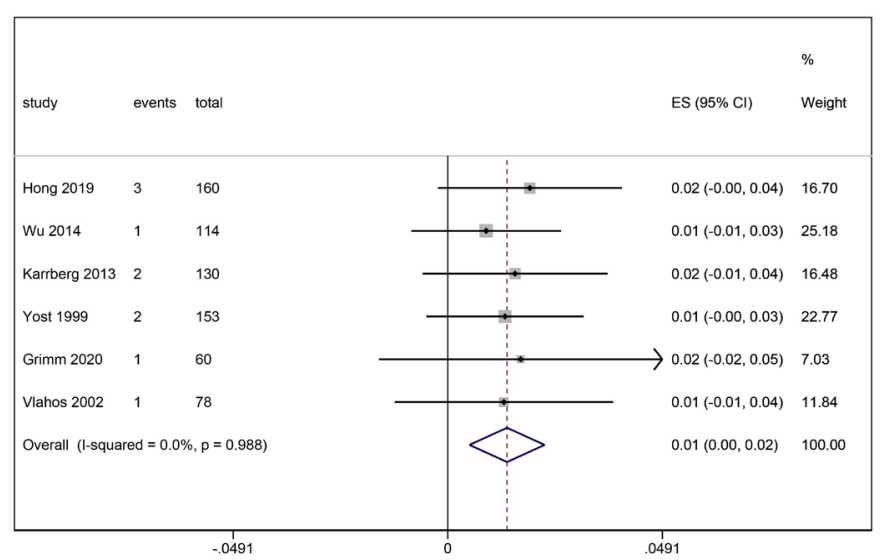

Figure 4 Forest plot of progression rates of high-grade CIN. $\mathrm{CIN}$, cervical intraepithelial neoplasia.
We carried out the first systematic appraisal of the published data on the natural history of histologically confirmed high-grade CIN lesions during pregnancy. By scientifically statistically pooling the rates of regression, persistence and progression, our study provides gynaecologists and pregnant women the current best estimates of the different prognoses of high-grade CIN during pregnancy to assist consultation and shared decision-making. The major strength of our study is the scientific and rigorous methodology. The literature searches, identification of eligibility, data extraction and quality assessment of included studies were all independently performed by different reviewers of our team. We employed reasonable statistical methods to produce pooled estimates and appropriately 
addressed the moderate-to-high heterogeneity among the included studies by using subgroup meta-analyses. What is more, in consideration of the fact that the sensitivity and specificity of cytology are lower than that of histology ${ }^{54}$ we only included the studies that had histological diagnoses of high-grade CIN, thereby reducing the risk of misclassification bias.

However, several limitations need to be considered when interpreting the results of our study. First, there was some degree of heterogeneity across the included studies in baseline characteristics (eg, the duration of postpartum follow-up), definitions of outcomes and methods of cervical assessment after delivery. Second, the included studies could not provide specific data on the gestational ages or the number of cervical screenings during the follow-up. The duration of pregnancy may have some effects on the natural course of high-grade CIN. Also, it is well known the one biopsy taken during colposcopy underestimates the incidence of high-grade cervical lesions. Third, we should be cautious with these results because the majority of included studies were small scale, additional large sample and multicentre studies are needed to confirm the results from our studies. Finally, no study published in other languages was included in our systematic review and meta-analysis because of limited resources and our restricted linguistic capacity.

\section{CONCLUSIONS}

During pregnancy, the majority of histologically confirmed high-grade CIN will be persistent or regressed to lower grade CIN or normal. It is worth noting that a small percentage of high-grade CIN will progress to more severe disease during pregnancy.

Contributors Conceptualisation-CC, YX, WH, YD and CH. Methodology-CC, $\mathrm{YX}, \mathrm{WH}, \mathrm{YD}$ and $\mathrm{CH}$. Data collection-CC and WH. Project administration- $\mathrm{YX}$. Supervision-YX. Writing (original draft) $-\mathrm{CC}$ and $\mathrm{YX}$. Writing (review and editing)$\mathrm{CC}, \mathrm{YX}, \mathrm{WH}, \mathrm{YD}$ and $\mathrm{CH}$.

Funding The authors have not declared a specific grant for this research from any funding agency in the public, commercial or not-for-profit sectors.

Competing interests None declared.

Patient consent for publication Not required.

Provenance and peer review Not commissioned; externally peer reviewed.

Data availability statement № data are available. Data are available upon reasonable request.

Supplemental material This content has been supplied by the author(s). It has not been vetted by BMJ Publishing Group Limited (BMJ) and may not have been peer-reviewed. Any opinions or recommendations discussed are solely those of the author(s) and are not endorsed by BMJ. BMJ disclaims all liability and responsibility arising from any reliance placed on the content. Where the content includes any translated material, BMJ does not warrant the accuracy and reliability of the translations (including but not limited to local regulations, clinical guidelines, terminology, drug names and drug dosages), and is not responsible for any error and/or omissions arising from translation and adaptation or otherwise.

Open access This is an open access article distributed in accordance with the Creative Commons Attribution Non Commercial (CC BY-NC 4.0) license, which permits others to distribute, remix, adapt, build upon this work non-commercially, and license their derivative works on different terms, provided the original work is properly cited, appropriate credit is given, any changes made indicated, and the use is non-commercial. See: http://creativecommons.org/licenses/by-nc/4.0/.

\section{ORCID iD}

Yu Xu http://orcid.org/0000-0001-9819-1965

\section{REFERENCES}

1 Gravitt P, Winer R. Natural history of HPV infection across the lifespan: role of viral latency. Viruses2017;9:267.

2 Schiffman M, Wentzensen N, Wacholder S, et al. Human papillomavirus testing in the prevention of cervical cancer. $J$ Natl Cancer Inst 2011;103:368-83.

3 Kjær SK, Frederiksen K, Munk C, et al. Long-term absolute risk of cervical intraepithelial neoplasia grade 3 or worse following human papillomavirus infection: role of persistence. $J$ Natl Cancer Inst 2010;102:1478-88.

4 Insinga RP, Glass AG, Rush BB. Diagnoses and outcomes in cervical cancer screening: a population-based study. Am J Obstet Gynecol 2004;191:105-13.

5 Douvier S, Filipuzzi L, Sagot P. [Management of cervical intraepithelial neoplasm during pregnancy]. Gynecol Obstet Fertil 2003;31:851-5.

6 Morimura Y, Fujimori K, Soeda S, et al. Cervical cytology during pregnancy-comparison with non-pregnant women and management of pregnant women with abnormal cytology. Fukushima J Med Sci 2002;48:27-37.

7 Al-Halal H, Kezouh A, Abenhaim HA. Incidence and obstetrical outcomes of cervical intraepithelial neoplasia and cervical cancer in pregnancy: a population-based study on 8.8 million births. Arch Gynecol Obstet 2013;287:245-50.

8 Origoni M, Salvatore S, Perino A, et al. Cervical intraepithelial neoplasia $(\mathrm{CIN})$ in pregnancy: the state of the art. Eur Rev Med Pharmacol Sci 2014;18:851-60.

9 Fader AN, Alward EK, Niederhauser A, et al. Cervical dysplasia in pregnancy: a multi-institutional evaluation. Am J Obstet Gynecol 2010;203:113.e1-113.e6.

10 Smith LH, Danielsen B, Allen ME, et al. Cancer associated with obstetric delivery: results of linkage with the California cancer registry. Am J Obstet Gynecol 2003;189:1128-35.

11 Hunter MI, Monk BJ, Tewari KS. Cervical neoplasia in pregnancy. Part 1: screening and management of preinvasive disease. $A m \mathrm{~J}$ Obstet Gynecol 2008;199:3-9.

12 Bentley J, Bentley J, Bertrand MColposcopic management of abnormal cervical cytology and histology. J Obstet Gynaecol Can 2012;34:1188-202.

13 Hillemanns P, Friese K, Dannecker C, et al. Prevention of cervical cancer: guideline of the DGGG and the DKG (S3 level, AWMF register number 015/027OL, December 2017) - part 1 with introduction, screening and the pathology of cervical dysplasia. Geburtshilfe Frauenheilkd 2019;79:148-59.

14 Jordan J, Arbyn M, Martin-Hirsch P, et al. European guidelines for quality assurance in cervical cancer screening: recommendations for clinical management of abnormal cervical cytology, part 1. Cytopathology 2008;19:342-54.

15 Massad LS, Einstein MH, Huh WK, et al. 2012 updated consensus guidelines for the management of abnormal cervical cancer screening tests and cancer precursors. Obstet Gynecol 2013;121:829-46.

16 WHO Guidelines Approved by the Guidelines Review Committee. Comprehensive cervical cancer control: a guide to essential practice. Geneva: World Health Organization, 2014.

17 Perrone AM, Bovicelli A, D'Andrilli G, et al. Cervical cancer in pregnancy: analysis of the literature and innovative approaches. J Cell Physiol 2019;234:14975-90.

18 Murta EFC, de Souza FHC, de Souza MAH, et al. High-grade cervical squamous intraepithelial lesion during pregnancy. Tumori 2002;88:246-50.

19 Paraskevaidis E, Koliopoulos G, Kalantaridou S, et al. Management and evolution of cervical intraepithelial neoplasia during pregnancy and postpartum. Eur J Obstet Gynecol Reprod Biol 2002;104:67-9.

20 Chung SM, Son GH, Nam EJ, et al. Mode of delivery influences the regression of abnormal cervical cytology. Gynecol Obstet Invest 2011;72:234-8.

21 Everson JA, Stika CS, Lurain JR. Postpartum evolution of cervical squamous intraepithelial lesions with respect to the route of delivery. $J$ Low Genit Tract Dis 2002;6:212-7.

22 Moher D, Liberati A, Tetzlaff J, et al. Preferred reporting items for systematic reviews and meta-analyses: the PRISMA statement. BMJ 2009;339:b2535. 
23 Munn Z, Moola S, Lisy K, et al. Methodological guidance for systematic reviews of observational epidemiological studies reporting prevalence and cumulative incidence data. Int J Evid Based Healthc 2015;13:147-53.

24 Munn Z, Moola S, Riitano D, et al. The development of a critical appraisal tool for use in systematic reviews addressing questions of prevalence. Int J Health Policy Manag 2014;3:123-8.

25 Nyaga VN, Arbyn M, Aerts M. Metaprop: a Stata command to perform meta-analysis of binomial data. Arch Public Health 2014;72:39.

26 Higgins JPT, Thompson SG, Deeks JJ. Measuring inconsistency in meta-analyses. BMJ 2003;327:557-60.

27 Egger M, Smith GD, Schneider M, et al. Bias in meta-analysis detected by a simple, graphical test. BMJ 1997;315:629-34.

28 Yost MP, Santoso JT, Mclntire DD, et al. Postpartum regression rates of antepartum cervical intraepithelial neoplasia II and III lesions. Obstet Gynecol 1999;93:359-62.

29 Vlahos G, Rodolakis A, Diakomanolis E, et al. Conservative Management of Cervical Intraepithelial Neoplasia ( $\mathrm{CIN}<\mathrm{sub}>2-3<$ ) sub>) in Pregnant Women. Gynecol Obstet Invest 2002;54:78-81.

30 Serati M, Uccella S, Laterza RM, et al. Natural history of cervical intraepithelial neoplasia during pregnancy. Acta Obstet Gynecol Scand 2008:87:1296-300.

31 Ueda Y, Enomoto T, Miyatake T, et al. Postpartum outcome of cervical intraepithelial neoplasia in pregnant women determined by route of delivery. Reprod Sci 2009;16:1034-9.

32 Kärrberg C, Brännström M, Strander B, et al. Colposcopically directed cervical biopsy during pregnancy; minor surgical and obstetrical complications and high rates of persistence and regression. Acta Obstet Gynecol Scand 2013;92:692-9.

33 Wu YM, Wang T, He Y, et al. Clinical management of cervical intraepithelial neoplasia in pregnant and postpartum women. Arch Gynecol Obstet 2014;289:1071-7.

34 Mailath-Pokorny M, Schwameis R, Grimm C, et al. Natural history of cervical intraepithelial neoplasia in pregnancy: postpartum histopathologic outcome and review of the literature. BMC Pregnancy Childbirth 2016;16.

35 Schuster S, Joura E, Kohlberger P. Natural history of squamous intraepithelial lesions in pregnancy and mode of delivery. Anticancer Res 2018;38:2439-42.

36 Hong DK, Kim SA, Lim KT, et al. Clinical outcome of high-grade cervical intraepithelial neoplasia during pregnancy: a 10-year experience. Eur J Obstet Gynecol Reprod Biol 2019;236:173-6.

37 Grimm D, Lang I, Prieske K, et al. Course of cervical intraepithelial neoplasia diagnosed during pregnancy. Arch Gynecol Obstet 2020;301:1503-12.

38 Massad LS. New guidelines on cervical cancer screening: more than just the end of annual Pap testing. J Low Genit Tract Dis 2012;16:172-4.
39 Michael CW, Esfahani FM. Pregnancy-related changes: a retrospective review of 278 cervical smears. Diagn Cytopathol 1997;17:99-107.

40 Economos K, Perez Veridiano N, Delke I, et al. Abnormal cervical cytology in pregnancy: a 17-year experience. Obstet Gynecol 1993;81:915-8.

41 Baldauf J-J, Dreyfus M, Ritter J, et al. Colposcopy and directed biopsy reliability during pregnancy: a cohort study. Eur J Obstet Gynecol Reprod Biol 1995;62:31-6.

42 Ciavattini A, Serri M, Di Giuseppe J, et al. Reliability of colposcopy during pregnancy. Eur J Obstet Gynecol Reprod Biol 2018;229:76-81.

43 Lurain JR, Gallup DG. Management of abnormal Papanicolaou smears in pregnancy. Obstet Gynecol 1979;53:664-5.

44 Palle C, Bangsbøll S, Andreasson B. Cervical intraepithelial neoplasia in pregnancy. Acta Obstet Gynecol Scand 2000;79:306-10.

45 Suchonska B, Gajewska M, Madej A, et al. Cervical intraepithelial neoplasia during pregnancy. Indian J Cancer 2020;57:31-5.

46 Kaplan KJ, Dainty LA, Dolinsky B, et al. Prognosis and recurrence risk for patients with cervical squamous intraepithelial lesions diagnosed during pregnancy. Cancer 2004;102:228-32.

47 Zhang J, Lu C-X. Spontaneous regression of cervical intraepithelial neoplasia 2: a meta-analysis. Gynecol Obstet Invest 2019;84:562-7.

48 Tainio K, Athanasiou A, Tikkinen KAO, et al. Clinical course of untreated cervical intraepithelial neoplasia grade 2 under active surveillance: systematic review and meta-analysis. BMJ 2018;360:k499.

49 Bogani G, Sopracordevole F, Di Donato V, et al. High-risk HPVpositive and -negative high-grade cervical dysplasia: analysis of 5-year outcomes. Gynecol Oncol 2021;161:173-8.

50 Suchonska B, Gajewska M, Madej A, et al. Cervical intraepithelial neoplasia during pregnancy. Indian J Cancer 2020;57:31-5.

51 Athanasiou A, Veroniki AA, Efthimiou O, et al. Comparative fertility and pregnancy outcomes after local treatment for cervical intraepithelial neoplasia and stage $1 \mathrm{~A} 1$ cervical cancer: protocol for a systematic review and network meta-analysis from the CIRCLE group. BMJ Open 2019;9:e028009.

52 Papoutsis D, Underwood M, Parry-Smith W, et al. Early and late pregnancy outcomes in women treated with cold-coagulation versus LLETZ cervical treatment for cervical intraepithelial neoplasia; a retrospective cohort study. Arch Gynecol Obstet 2018;297:1015-25.

53 Fontham ETH, Wolf AMD, Church TR, et al. Cervical cancer screening for individuals at average risk: 2020 guideline update from the American cancer Society. CA Cancer J Clin 2020;70:321-46.

54 Carreon JD, Sherman ME, Guillén D, et al. CIN2 is a much less reproducible and less valid diagnosis than CIN3: results from a histological review of population-based cervical samples. Int $\mathrm{J}$ Gynecol Pathol 2007;26:441-6. 